\title{
Engineering practices as a framework for STEM education: a proposal based on epistemic nuances
}

\author{
Cristina Simarro ${ }^{*}$ (1) and Digna Couso
}

\begin{abstract}
The role of engineering education has gained prominence within the context of STEM education. New educational perspectives such as the National Research Council's Framework for K-12 Science Education consider engineering practices one of the central pillars of a sound STEM education. While this idea of developing a set of practices analogous to those of professional engineering resonates with recent views of STEM education research, current approaches such as the NRC's Framework seem too dependent on and interlinked with the list for scientific practices and adheres to this list too strictly. This paper draws on the NRC's Framework proposing a new set of engineering practices that seek to incorporate the epistemic nuances that differentiate engineering from science. The nine engineering practices proposed contain epistemological nuances that are missing in other proposals, including essential aspects such as problem scoping, identifying multiple solutions, selecting, testing and improving solutions and materializing solutions. This epistemic approach may facilitate students' content learning and thinking development, offering a more comprehensive and realistic view of the STEM fields.
\end{abstract}

Keywords: Engineering practices, STEM education, Epistemology, Nature of engineering

\section{Introduction}

The advocacy for STEM education has been pervasive in current educational debates. There is no doubt that the idea of giving relevance to Science, Engineering, Mathematics and Technology, whether integrated or not, has marked the direction of many educational policies and has been a topic of interest in the field of education research (Bybee, 2013; Johnson et al., 2020). Within this approach, and influenced by the perspective of design as a new twenty-first century literacy (Blikstein, 2013; Pacione, 2010), the role of engineering education has been modified, gaining more prominence and centrality in pre-college education ( $\mathrm{Li}$ et al., 2019; Pleasants \& Olson, 2019). This new role of engineering

\footnotetext{
*Correspondence: cristinarsimarro@gmail.com
}

Facultat de Ciències de l'Educació, Universitat Autònoma de Barcelona, Edifici G, Plaça del Coneixement, 08193 Bellaterra (Cerdanyola del Vallès), Barcelona, Spain in the education-for-all perspective is exemplified in the Framework of the National Research Council (2012) where a prominent place is given to engineering. In this framework, reflecting the importance of understanding the human-built world and recognizing the value of better integrating the teaching and learning of science, engineering, and technology are the reasons behind the elevation of engineering design to the level of scientific inquiry.

Some authors argue that engineering education can improve students' learning in science and mathematics (by providing, for example, a context in which to test scientific knowledge and apply it to practical problems), increase knowledge of engineering and the work of engineers, increase students' technological literacy, and stimulate young people's interest in pursuing engineering as a career. In relation to the idea of STEM education and the integration of its disciplines, there are those who believe that engineering education can act as a catalyst for more 
interconnected STEM education (King \& English, 2016; National Academy of Engineering \& National Research Council, 2009; National Research Council, 2012). However, critical voices have denounced the mismatch between the call for more and better engineers and the low presence of engineering education in compulsory education, especially in primary and lower secondary (Bagiati et al., 2015; Lucas et al., 2014).

In our opinion, some of the motivations and potential benefits of enhancing the presence of engineering in precollege education somewhat undermine the true raison d'être of this engineering education, which would, in turn, explain the shortcomings pointed out when it comes to engineering education. For instance, the perspective of engineering as a context is fundamentally based on an idea of education focused on the products of engineering as a discipline (e.g.: energy and power technologies). Frameworks such as those of Science, Technology and Society (Bybee, 1987) are based precisely on this perspective, where relevance is given to technology (the product of the engineering activity) and not to the engineering practices themselves, emphasizing the connection with other disciplines. Similarly, when technology and engineering are placed at the heart of an integrated STEM education there is an imbalance in the focus on the different STEM disciplines (Honey et al., 2014), with engineering and technology often gaining more centrality (Becker \& Park, 2011) and science and mathematics being used as contexts or tools for tackling technological design problem-solving (English, 2016; Sokolowski, 2018).

As a result, current STEM education tends to focus on the use of technology per se instead of promoting a way of intervening in relevant social contexts. Hence, engineering and technology education, and STEM education as a consequence, has been criticized for offering a techno-centric view where, for instance, the use of creative technologies is the main concern (a distorted understanding of the $\mathrm{T}$ in STEM, identified only as computing (Sanders, 2009)). This approach moves away from a literacy perspective of STEM education for all and tends to alienate some profiles that are expected to be attracted to STEM disciplines, and especially to engineering, such as girls (Moote et al., 2020).

In consequence, there is a growing consensus that engineering education should follow the example of science education by engaging students in disciplinary practices (Cunningham \& Carlsen, 2014a; National Research Council, 2012), that is, engage them more in its processes than in its products. Recognizing engineering as a cognitive, social and cultural activity (Bucciarelli, 2003) implies recognizing that it encompasses specific practices, that is, specific ways of doing, talking, thinking, valuing and being (Couso \& Simarro, 2020). From this sociocultural perspective of education, in the same way that scientific practices are seen as a core content for science education (Duschl \& Grandy, 2013; Osborne, 2014), the participation of students in school-based engineering practices analogous to those of the professional engineering world becomes a central element of 21st engineering education.

\section{From engineering process to engineering practices}

Seeking to help young students engage in engineering design as a new literacy (English \& King, 2015), several design and engineering design process models have been recently developed in formal and non-formal contexts, specifically for young grades (primary and lower secondary) (Dorie et al., 2014; English \& King, 2015). While based on an old-fashioned step-by-step approach, and hence far from the idea of learning engineering as participating in a complex and rich cultural practice, it is interesting to identify similarities and differences between these processes. Table 1 summarizes some of these engineering processes, highlighting commonalities and divergences.

Most of these models, for instance, include the idea of scoping the problem, defining the constraints and criteria to bear in mind. While relevant in solving engineering problems in the workplace, little attention is usually given to this engineering activity, especially for young learners (Dorie et al., 2014). According to research, problem scoping differentiates experts from novices, with the former spending more time engaged in this type of activities that may lead to higher-quality engineering design solutions (Atman et al., 2007). Problem scoping may entail, among others, clarifying and restating the goal of the problem, identifying constraints to be met, exploring feasibility issues and drawing on related context to add meaning (English \& King, 2015).

Some of the models of the engineering process also refer to the existence of more than one possible solution which entails the need for a selection process based on the defined criteria. This selection process includes the consideration of what others have done to solve the problem, including prior research, and brainstorming for generating new ideas for solutions (NASA, 2009). The idea of building a prototype for testing is also present in some of these engineering processes. In contrast to the idea of a descriptive or interpretative model, which is used to demonstrate or explain how a product will look or function, a prototype is used to test different working aspects of a product before the design is finalized (TeachEngineering, 2009). Prototyping is considered an activity undertaken by informed designers, and that is an essential part of the design process (Crismond \& Adams, 2012). Finally, only two of the models refer to the need to communicate, understood 


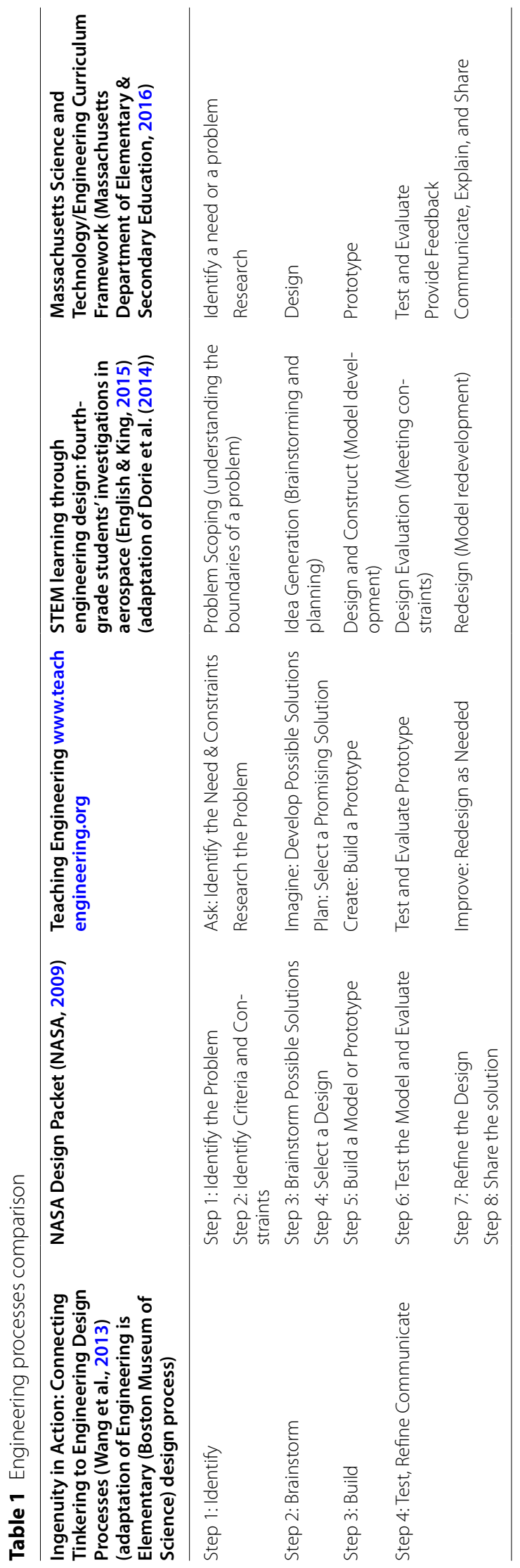


as an essential activity for conveying how the solution solves the identified need or problem and meets the criteria and constraints (Massachusetts Department of Elemantary \& Secondary Education, 2016).

Regardless of the degree of completeness with which the steps included in the different versions of the engineering process summarized in Table 1 are followed, the main problem that we see in common in all of them is that they are focused to sequence a process that can be applied to solve any problem (even those which are not from engineering). Hence, they lack an approach that sees engineering not only as a single set of procedures but as an idiosyncratic and complex cognitive, social and discursive cultural activity with its own tools and rules. The eight engineering practices proposed by the National Research Council (2012) go one step beyond the idea of engineering process to present engineering as the participation in a set of practices which require the simultaneous coordination of both knowledge and skills:

1. Defining problems

2. Developing and using models

3. Planning and carrying out investigations

4. Analyzing and interpreting data

5. Using mathematics and computational thinking

6. Designing solutions

7. Engaging in argument from evidence

8. Obtaining, evaluating, and communicating information

Despite the crucial paradigm shift that entails viewing the teaching and learning of engineering not as the mastery of a generic problem-solving approach but as the promotion of active student participation in engineering practices, we consider the NRC engineering framework insufficient. The main reason is that the list of practices are too dependent on and interlinked with the list for scientific practices: only two practices are specific to engineering (defining problems and designing solutions) while the rest are exactly the same for both science and engineering. In this regard, and from an epistemic viewpoint, we strongly disagree with authors, such as Bybee (2011), who claim that with the exception of their goals, science and engineering practices are parallel and complementary. As Cunningham and Carlsen (2014b) argue, we believe that a subtle differentiation between science and engineering does not capture the epistemic differences between the two disciplines, and thus does not reflect certain salient engineering values that are essential to the engineering discipline and, at the same time, differentiate it from other disciplines (Couso \& Simarro, 2020).
Surprisingly, if a complete reading of the NRC framework is made, some of these differences can be grasped. For example, when discussing models, the framework introduces the concept of the prototype as a key element in engineering (as it occurred in the engineering processes compared above). From this perspective, one can evaluate the different role that the model idea plays in both disciplines: for science, a model is a key element and is part of the final product of its practice, whereas in engineering, a model is a tool to test a simplified version of the solution before its final release. A scientific model is a conceptual structure that represents a phenomena in order to describe, predict and explain it (Oh \& Oh, 2011). As such, it is a reasoning artefact which is the product of the practice of modelling (Couso \& Garrido-Espeja, 2017). An example is the Bohr model of the atom, which can be expressed in terms of drawings, written accounts, physical models (such as a play dough one) and others. Conversely, an engineering model (prototype) is intended to describe systems to be built and has evaluation as its primary objective (Combemale et al., 2016; Jensen et al., 2016). Small scale constructions or alpha versions in software developments are some examples of prototyping in engineering. Similarly, the importance of optimization in engineering is also emphasized, highlighting the existence of multiple solutions to the same problem and the selection of one based on a balance between the constraints and specifications defined in each case. While not labelled as optimization, this idea is also present in the step-by-step approaches to the engineering method reviewed previously. In contrast, science is always looking for the simplest and most explanatory solution, with the goal of science being to find a single theory that applies in a complete and coherent way to a large number of related phenomena. This fact also involves differences at the level of argumentation made by scientists and engineers: while in the first case the argumentation seeks to rule out possible alternative explanations based on multiple tests, in the second the main thing is to justify the choice made, evaluating prospective designs and producing the most effective design to meet specifications and constraints (National Research Council, 2012).

Despite the differentiation made in the text, the list of eight engineering practices proposed in the NRC curriculum framework do not sufficiently emphasize the important differences between both disciplines, science and engineering (Cunningham \& Carlsen, 2014a), and their statements, built in the image and likeness of scientific practices, do not encapsulate key elements of the nature of the engineering activity. Given the relevance that the list of eight engineering practices has on educational standards and curriculum designs, we consider the need for a new conceptualization of engineering practices in 
which the idiosyncratic differences between science and engineering are reflected. This is not to avoid an interdisciplinary STEM teaching approach where both science and engineering are considered, but to help teachers to improve students' understanding and knowledge both of and about engineering either in disciplinary or interdisciplinary oriented curricula.

\section{Including epistemic nuances to the idea of engineering practices}

A rich engineering education that educates not only in engineering but also about engineering needs to entail an epistemic view of the discipline, that is the range of practices, methodologies, aims and values, knowledge and social norms that characterize the disciplines (Erduran \& Dagher, 2014). In this regard, and as we have published elsewhere (Couso \& Simarro, 2020), STEM education would strongly benefit from taking an epistemological perspective that emphasizes the differences between science and engineering, in order to better understand the relationship and inter-dependence between both disciplines.

Table 2 summarizes main epistemic differences between science and engineering disciplines (Couso \& Simarro, 2020). Without going into detail, we highlight here some of these differences. Regarding their Aim, which can be considered the main distinctive characteristic between disciplines (Park et al., 2020; Sinclair, 1993), science and engineering pursue goals of a distinct nature. Science focuses on developing theoretical descriptions and constructing reliable explanatory frameworks of the natural world in order to understand and act upon it. Engineering has as a primary aim the construction of optimal human-made solutions. Hence, engineering objects of knowledge are human-made artefacts, including their study in functional terms and their construction (Boon, 2006; Bunge, 2017; Hansson, 2007, 2015; National Research Council, 2012; Sharp, 1991). The different nature of the aim of each discipline entails that while engineering solutions need to be concrete, operational and feasible today, a scientific explanatory framework such as a theory or model can only be abstract and conceptual. Furthermore, despite the evidence-based nature of models or theories, their connection to reality can be researched much later than their theoretical envisioning. Derived from each discipline's aim, different Spheres of Activity are identified for science and engineering that follow their respective aims. Scientific activity is characterized by three interconnected fields of action that involve the socio-discursive and reasoning processes of: inquiry, argumentation and modelling (Duschl \& Grandy, 2013; Osborne, 2014). Engineering practices take place in the creation (problem scoping and solution generation), the evaluation (assessment and selection) and the realization (making and bringing ideas to life) spaces (Dym et al., 2005).

These core activities result in specific scientific and engineering Forms of Knowledge. Principles, theories, laws, models and facts are recognized forms of knowledge that work together in generating and validating scientific explanations (Erduran \& Dagher, 2014) while mechanisms, processes and technologies could be understood as the way knowledge is encapsulated in engineering, both as a source and product of the engineering activity. Although less work has been done regarding the nature of engineering in order to establish the forms of knowledge that are important for this field, many authors agree on considering that engineering generates knowledge for

Table 2 Epistemic features of science and engineering (based on Couso \& Simarro, 2020)

\begin{tabular}{|c|c|c|c|}
\hline Epistemic feature & Description & Science & Engineering \\
\hline Aim & Main purpose of the discipline & $\begin{array}{l}\text { Construct reliable explanations of } \\
\text { natural phenomena }\end{array}$ & $\begin{array}{l}\text { Construct of human-made optimal } \\
\text { solutions }\end{array}$ \\
\hline Spheres of Activity & $\begin{array}{l}\text { Main areas of activity or fields of action } \\
\text { of the discipline carried out to pursue } \\
\text { its aim }\end{array}$ & Inquiry, argumentation and modelling & Creation, evaluation and realization \\
\hline Forms of Knowledge & $\begin{array}{l}\text { Types of products generated by and } \\
\text { used for the activities of the discipline } \\
\text { to answer the discipline's aim }\end{array}$ & Theories, laws, models, etc & Technologies, processes, etc \\
\hline Values and Quality Criteria & $\begin{array}{l}\text { Epistemic objectives of the discipline } \\
\text { that ensure its value and quality }\end{array}$ & $\begin{array}{l}\text { Accuracy, objectivity, universality, } \\
\text { theoretical consistency, coherence, } \\
\text { simplicity, empirical adequacy, validity } \\
\text { and reliability }\end{array}$ & $\begin{array}{l}\text { Practical success of a technical solution: } \\
\text { applicability, reliability, effectiveness } \\
\text { and efficiency }\end{array}$ \\
\hline Methodological Rules & $\begin{array}{l}\text { Main rules that guide the way activities } \\
\text { are done and knowledge is generated } \\
\text { and used within the discipline }\end{array}$ & $\begin{array}{l}\text { Hypothesis should be testable (theo- } \\
\text { retically or with real experiments) } \\
\text { There has to be convergence of a vari- } \\
\text { ety of evidence supporting a claim }\end{array}$ & $\begin{array}{l}\text { Solutions should be testable (no room } \\
\text { for idealization) } \\
\text { Solutions need to be comparable in } \\
\text { terms of applicability, efficiency and } \\
\text { efficacy }\end{array}$ \\
\hline
\end{tabular}


use in design, thus related to specific technologies: how particular technologies function, analytical tools and models that can be applied to a range of technological phenomena,... (Pleasants \& Olson, 2019; Vincenti, 1990). Values and Quality Criteria are again specific aspects that characterize science and engineering. The descriptions and interpretations constructed by science intend to be accurate, universal, simple, coherent, mutually consistent and based on evidence in an adequate, valid and reliable way. Therefore, scientific explanatory, descriptive and predictive frameworks are successful as far as they are adjusted to these values (even theoretically) regardless of their immediate practical application. In contrast, engineering values are closely connected to the practical feasibility and success of the engineered solution. Success is measured by the extent to which a technical solution provides an answer to a problem addressed in an optimal way, in terms of applicability, reliability, effectiveness and efficiency (Boon, 2006; Erduran \& Dagher, 2014; National Research Council, 2012).

Finally, and influenced by the characteristics of other dimensions, both science and engineering follow specific Methodological Rules that meet these values and quality criteria. In science, these methodological rules basically refer to the sophisticated ways in which theory, data and evidence should be coordinated. For engineering, where there is less room for idealization, other methodological rules apply. Of particular importance is the need for actual testing of the diverse proposed solutions (Hansson, 2007; National Academy of Engineering \& National Research Council, 2009).

All these dimensions-spheres of activity, forms of knowledge, values and quality criteria, and methodological rules-influence the more visible and recognizable characteristics of science and engineering. Science and engineering Practices, Knowledge, Ethos and Methods are the characteristics of the disciplines that are more context-dependent and, as such, less idiosyncratic. In this regard, some overlap exists in the way we define these characteristics in different disciplines which could explain, for instance, the interdependence between scientific and engineering practices proposed by the NRC framework and evident in the many fields that combine both, such as nanotechnology or bioengineering.

\section{Towards a more comprehensive account of engineering practices}

Several voices have identified the lack of epistemic emphasis on the engineering PreK-12 standards and the imbalanced presence of disciplines in STEM education (Cunningham \& Carlsen, 2014a, 2014b; ITEEA \& CTETE, 2020). As a result, new educational proposals have recently been emerging. A clear example is the new
Standards for Technological and Engineering Literacy developed by the International Technology and Engineering Educators Association (ITEEA) and the Council on Technology and Engineering Teacher Education (CTETE) (2020). These new standards acknowledge the epistemological basis of engineering and technology and propose a new framework which also includes engineering (and technological) practices as one of its organizers. However, while these practices are seen as key attributes and personal qualities that all technology and engineering students should exhibit, they are, in our opinion, more based on the idea of skills and competences (e.g.: collaboration, communication, creativity...) rather than on the discipline's spheres of activity that characterize the NRC idea of practices.

In this regard, while recognizing the shortcomings of the NRC engineering practices highlighted before, we draw on them to propose a new set of engineering practices that seek to incorporate the epistemic nuances discussed above. Bearing in mind these epistemological differences, especially in terms of spheres of activity, as well as the approaches that address to some extent the idea of engineering process (Table 1), we propose a set of nine engineering practices that emphasize some of the key elements that, from our point of view, should be included in the idea of engineering practices (Table 3).

What follows is a summary of the main ideas included in our proposal. Their description does not follow the order of the practices as presented in the NRC's framework but is based on the nature of the proposed changes: for some practices a new definition has been proposed or expanded (e.g.: defining problems and designing solutions), while for others only some concepts have been nuanced (e.g.: models vs. prototypes or simulations and investigations vs. tests) or have been even integrally kept (engaging in argument from evidence and obtaining, evaluating, and communicating information).

\section{From defining problems to defining and delimiting problems} Expanding the idea of problem definition, this proposal highlights the need for delimiting problems, that is, establishing what constraints need to be considered when thinking about possible solutions. Hence, Defining Problems practice becomes Defining and Delimiting Problems which, in fact, is already stated as one of the engineering core ideas, including the emphasis given to this core idea of specifying clear criteria within the practice itself. Delimiting includes the concept of systems thinking because it limits the scope and allows definition of the restrictions and the criteria of success. In our opinion, this way of defining a problem, including its explicit delimitation, is not trivial since "Many such problems (to which engineers are invited to solve) (...) are ill-defined 
Table 3 Alternative proposal to the NRC Engineering Practices

\begin{tabular}{ll}
\hline NRC $\mathbf{2 0 1 2}$ practices definition & Alternative proposal $^{\mathbf{1}^{1}}$ \\
\hline Defining problems & Defining and delimiting engineering problems \\
Developing and using models & Developing and using prototypes and simulations \\
Planning and carrying out investigations & Planning and carrying out tests \\
Analyzing and interpreting data & Analyzing and interpreting data to identify points for improvement \\
Using mathematics and computational thinking & $\begin{array}{l}\text { Using mathematics and computational thinking, scientific models } \\
\text { and available technologies }\end{array}$ \\
Designing solutions & $\begin{array}{l}\text { Identifying and/or developing multiple solutions and selecting } \\
\text { the optimal one }\end{array}$ \\
- & Materializing the solution \\
Engaging in argument from evidence & Engaging in argument from evidence \\
Obtaining, evaluating, and communicating information & Obtaining, evaluating, and communicating information
\end{tabular}

${ }^{1}$ Changes highlighted in bold

or wicked problems, meaning that it is not at all clear what the problem is exactly and what a solution to the problem would consist in" (Franssen et al., 2018). Moreover, the idea of delimitation suggests the need to consider a holistic approach to engineering problem-solving, presented as an open system that requires considering all aspects and perspectives not only of artefacts and users, but also their effects on the environment, individuals, and society and culture (Karatas et al., 2011). As Hansson (2007) points out, engineering often deals with concepts loaded with value such as user-friendliness, respect for the environment, or risk. This problem framing is seen by research as a crucial difference between experienced and novice designers (Crismond \& Adams, 2012), influencing the entire design process.

As an example, beyond asking students to define the problem to be solved (what is needed, what is the purpose, what are the functions that a solution must accomplish...) we ask them to bear in mind the context in which the problem takes place. This may entail considering constraints related to sustainability and economy, understanding end-users' characteristics or assessing resources at hand. Allowing students to assess the suitability of existing solutions, considering several constraints, could help students in elementary levels to start thinking beyond intrinsic solution variables as constraints while more advanced students could be faced with complex contexts in which they identify nonobvious needs or constraints.

\section{From designing solutions to identifying and/or developing multiple solutions and selecting the optimal one}

In regard to the idea of designing solutions, the practices proposed by the NRC present, from our point of view, a fundamental problem, also applicable to scientific practices. In our opinion, the idea of designing solutions (for engineering) or building explanations (for science) is too generic as a practice and, in fact, is basically the goal (aim) of each discipline as we have previously discussed. Looking to offer an alternative that includes some of the key aspects highlighted for engineering, in our proposal we have raised the idea of identifying and/or developing multiple solutions and selecting the optimal one. This specification is based on the understanding that, in engineering, solutions are never unique and that only by considering the constraints posed in the delimitation of the problem (and from a holistic perspective as discussed above), can one choose a desired solution to consider and to bet on, for example, the realization of prototypes and tests.

With elementary students this practice can be developed by comparing existing solutions to a similar need (for instance, comparing electric cars with internal combustion engine vehicles or diverse heating systems) and discussing according to which constraints each solution would be optimal. Higher level students may define their own solutions and compare them with others to finally decide which is the best solution given specific constraints and considering trade-offs among them. The objective is to see that diverse solutions are possible but only few of them offer trade-offs levels that make them eligible. Developing this practice with students and embracing their different solutions to the same problem helps to enhance the epistemic idea that there are multiple solutions to the same engineering design problem and that the optimal solution can change depending on the criteria and constraints considered.

\section{From using mathematics and computational thinking to including scientific models and available technologies} Similarly, and regarding the practice of using mathematical thinking and computational thinking, our proposal 
adds two ideas that would also be useful for scientific practices: the use of scientific models and available technologies. According to this, both the results of the scientific (models) and engineering (technologies) activity also serve as a resource to achieve each of the respective aims of both disciplines. This approach is more in line with the idea of STEM as a field in which their disciplines share common grounds and are profoundly interrelated, despite not being the same. Moreover, and in the case of engineering, it acknowledges how understanding the natural world may help engineering processes and technologies to improve and make visible the nature of technology as an evolution and combination of previous technologies (Arthur's combinational evolution (Arthur, 2011)).

Developing this practice among students should encompass the analysis of the evolution of current technologies, understanding how scientific advances explain technology transitions as well as identifying which technologies enabled the conceptualization of new solutions (for example, how radio wave communication revolutionized global communication systems). Older students should also take advantage of their scientific, technological and mathematical knowledge to define and optimize their own solutions.

\section{From models and investigations to prototypes, simulations and tests}

Additionally, our proposal adds nuance to some of the words commonly used for scientific and engineering practices. On the one hand, with regard to models, there has been an attempt to avoid confusion with the idea of scientific model because we believe that the "models" used in engineering (to test possible solutions and to look for points for improvement) differ greatly from the idea of scientific models. Thus, we propose the terms prototypes and simulations, following some of the curricular proposals presented above. On the other hand, there has also been an attempt to avoid the use of the word investigation which could be easily linked to the idea of inquiry. Given the relevance of this concept of inquiry for science teaching we alternatively propose to talk about testing. Beyond a trial-and-error approach, engineering testing also requires a thoughtful plan, considering the variables to be considered for answering the posed questions. However, while science investigations seek to obtain evidence for confirming existing theories and explanations or to revise and develop new ones, engineering tests aim to validate the performance of a solution given specific constraints. Hence, while scientific inquiry uses evidence for assessing the world of ideas, engineering tests obtains evidence from and to the world of objects.

\section{From analyzing and interpreting data to identifying points of improvement}

Seeking to emphasize the idea of optimization, so relevant to engineering, the practice of analyzing and interpreting data has been nuanced with the identification of points for improvement, considering the need to respond to the constraints identified in delimiting the problem. As discussed above, engineering solutions are less idealized than scientific explanations. In this regard, the best engineering solution is charged with diverse values beyond its efficacy, which influence a diverse number of trade-offs to be assessed and tackled before confirming the suitability of the solution. Hence, the analysis and interpretation of data is made in light of this optimal solution and not only to see if data obtained through engineering test confirm whether a solution is suitable or not.

\section{Engaging in argument from evidence and obtaining, evaluating, and communicating information}

The three last practices discussed above (development of prototypes and simulations, planning of tests and analysis for the identification of points of improvement) are those more related to the hands-on nature traditionally linked to technology and engineering as an educational subject. However, these practices are not minds-off. While they usually occur in the world of objects (with tests carried out with physical prototypes or simulations) these practices are also loaded with ideas, including the hypothesis made while defining the tests to carry out. These hypotheses will be linked to the constraints and contexts considered when delimiting the problem. In this regard, beyond activities addressed to prototyping and simulating (with the emerging creative technologies such as $3 \mathrm{D}$ printing or block programming solutions) we must present students with activities in which they define the criteria for success and design reliable tests in order to obtain evidence. This evidence and the quality of the conducted tests will in turn be central to arguments used while communicating the suitability of one solution. In our proposal, the practices of building arguments based on evidence and obtaining, evaluating and communicating information have been maintained, as it has not been considered necessary to make any clarifications or add nuance in relation to scientific practices beyond the assumption that both engineering evidences and tests have a different nature to scientific evidences and inquiry processes.

\section{Materialization: a new practice}

Finally, our proposal includes a ninth practice, not considered in the NRC list, which involves the idea of nonidealization in engineering solutions: the materialization of the solutions. The challenge of moving from a desired 
function for a technology to the real structure that will produce that desired function is seen as a mysterious practice that can not be achieved mechanistically or algorithmically but that requires great creativity (Pleasants \& Olson, 2019). Hence, this ninth practice of materialization seeks to encapsulate this creative but strongly constrained process of grounding the theoretical ideas about the solutions considering the actual technological and socio-economic limits of the context in which the problem is being solved, which include the actual available or affordable resources (e.g.: materials at hand to use in order to have a low environmental or economic impact). This materialization practice focuses not only on the construction of the solutions themselves (bringing them to life, as some authors say) but includes what some authors have called visualization, an engineering habit of mind that refers to the ability to move from the abstract to the concrete, that is, how to concretize an idea to arrive at a practical solution, including the selection and manipulation of real materials (Lucas et al., 2014). At this regard, while we agree with Cunningham and Kelly (2017) that one core feature of potential solutions that must be carefully weighed to the non-ideal solutions of engineering is what materials the technology is made from and consequently that the practice of considering materials and their properties is a core engineering practice, we think that this idea of materialization as a creative process goes beyond materials and encompasses all the concepts or engineering knowledge that may help realizing the solution (including, for instance, the processes to be used). And it is that making and doing are at the heart of what makes technology and engineering so different from other fields, including skills such as manipulating materials and effectively using hand and power tools (ITEEA \& CTETE, 2020). This materialization practice is a broader practice included in the third sphere of activity in which, according to some authors, the engineering design process takes place: creation, evaluation and realization (Dym et al., 2005). Thus, from our point of view, this materialization practice is an important difference between science and engineering, being one of the engineering spheres of activity highlighted above, which is not captured in the eight practices proposed by the NRC's framework.

Developing this materialization among students goes beyond the construction process itself and must encompass a critical selection, acquisition and treatment of materials and the organisation and participation in the processes to be used when turning student solutions into reality. Younger students must be trained in such practice by critically analysing existing technologies or solutions and discussing if the materials used are the most suitable for the solution's purpose and considering available resources such as environment (e.g.: comparing diverse plastic water bottles). Older students would face real challenges in which they decide which of the resources at hand could be used for implementing their theoretically designed solution.

\section{Conclusions}

PreK-12 engineering education is still under development. While recent efforts such as the inclusion of engineering practices in the NRC Framework (2012) or the recent Standards for Technology and Engineering Literacy (ITEEA \& CTETE, 2020) confirm an ascending trend of the role of engineering in STEM education, the truth is that engineering is still commonly underrepresented and misunderstood, particularly in pre-college education for all. In our opinion, this misrepresentation is due to a lack of epistemological view of disciplines, which hinders a rich view of the nature of each of the STEM disciplines (Couso \& Simarro, 2020; Erduran, 2020). In the case of engineering, this imbalance is exemplified in the dependence of the engineering practices proposed by $\mathrm{NRC}$, which are mainly based on disciplines similarities instead of essential disciplinary differences (Cunningham \& Carlsen, 2014b; Cunningham \& Kelly, 2017).

Our proposal has tried to apply the centrality given by the NRC framework to the idea of practices as the spheres of activity of engineering that we want to analogically develop with our students. While similar work has been done in the same direction, like the suggestive epistemic practices of engineering for education proposed by Cunningham and Kelly (2017), our proposal has been intended to take advantage of the already existing NRC framework which is influencing many standards and is being integrated by teachers. The nine engineering practices that we have proposed embed the epistemological load that is missed in other proposals, including essential aspects such as problem scoping, identifying multiple solutions, selecting, testing and improving solutions and materializing solutions. In this proposal, design is not only a part of the practices, but the overarching practice linked to the engineering actual disciplinary aim. In our opinion, STEM educators will benefit from the emphasis given to engineering disciplinary idiosyncrasy because it will allow them to promote a sound STEM education that offers a more comprehensive and realistic view of all the STEM fields (Ortiz-Revilla et al., 2020). As Li and colleagues argue, educational research would benefit from a better identification, examination, and comparison of specific epistemic practices pertinent to different disciplines in STEM to facilitate students' content learning and thinking development (Li et al., 2019). In the specific case of engineering, epistemic beliefs about engineering (nature of engineering (NOE) views) can influence 
students' learning and a better understanding of NOE is a crucial component of engineering literacy (Deniz et al., 2019). In this regard, the set of engineering practices presented in this paper seeks to enhance students' NOE views in order to allow them to better appreciate epistemic aspects of the engineering design process. Being able to integrate practices of the different STEM disciplines is one of the desirable outcomes of a sound STEM education, which would not happen adequately without a clear epistemological approach.

However, the development of engineering practices is only a portion of what a rich engineering education may offer in order to achieve high levels of engineering literacy among students. The development of engineering practices is beneficial not only in terms of the content of the practices themselves, but is also useful for learning other relevant conceptual content such as the central ideas of engineering. In this regard, more work has to be done if we want engineering to have a more prominent status within STEM disciplines not only by adding a technological component or providing interesting "ways of doing", but also by providing conceptual artefacts and tools to think about the world and act on the world.

Unfortunately, the imbalance between science and engineering is also evident when it comes to the socalled core ideas. Presented in the NRC framework as the key important concepts of each discipline, and following the philosophy of Harlen's big ideas of science (Harlen, 2010), these core ideas are, together with the idea of scientific and engineering practices and crosscutting concepts, one of the three dimensions of the Framework. However, while in the case of science a total of eleven key ideas with their corresponding subideas are included within the scientific core ideas, only two core ideas are listed for engineering, the first being very close to the idea of practice (engineering design) and the second being the interrelation between engineering, technology, science and society. Hence, while identified as core ideas, the truth is that they do not correspond to the definition of a core idea. As Cunningham and Carlsen (2014b) point out regarding the first engineering core idea (ETS1: Engineering Designs) it sounds like activities-defining and delimiting an engineering problem, developing possible solutions, and optimizing the design solution- and not like concepts, principles, or theories. Moreover, the second core idea (ETS2: Links Among Engineering, Technology, Science, and Society) is far from being a central idea of engineering, but is instead a reflection about the relationship between both science and engineering that: (1) is not included in science core ideas, and (2) gives the idea, according to how it is specified, of engineering and technology as a mere application of science
(Ortiz-Revilla et al., 2020). Again, the effort of equating engineering and technology contents to science content is limited by the lack of an epistemological view.

The new Standards for Technological and Engineering Literacy (ITEEA \& CTETE, 2020) seek to broaden the concept of engineering core concepts. However, in our opinion, they fail to propose operational dimensions and categories for such core concepts, mixing elements of diverse nature (some related to practices (resources, requirements, trade-off, optimization), other elements related to cross-cutting concepts (system and process) and others more related to specific technologies (control)).

Perspectives about how technologies are developed (including the exploitation of natural resources), their nature (how they are and how they are used) and their applications (in which contexts they are used and the particularities that characterize each context) could be pillars to support a robust framework for defining the missing engineering core ideas.

Finally, our work has been focused on engineering literacy. While the links between engineering and technology are blurred, sometimes leading to discussions about technological and engineering literacy as a whole (ITEEA \& CTETE, 2020), we believe that some reflection should also be done in order to deepen on the understanding of their differences. As mentioned previously, engineering practices such as the ones proposed in this paper are built under the umbrella of design as the core practice of engineering, related to the engineering aim of constructing optimal solutions. Considering technology as a field that, rather than designing them, uses human-designed products, systems, and processes to modify the natural environment in order to satisfy needs and wants (ITEEA \& CTETE, 2020), a person literate in technology should perhaps develop specific technological practices which could be linked to, but different from, engineering ones.

\section{Abbreviations}

STEM: Science, Technology, Engineering and Mathematics; NRC: National Research Council; ITEEA: International Technology and Engineering Educators Association; CTETE: Council on Technology and Engineering Teacher Education; NOE: Nature of Engineering.

\section{Acknowledgements}

This work was supported by the Spanish Government Project ESPIGA [PGC2018-096581-B-C21], within the ACELEC research group [2017SGR1399].

Authors' contributions

Both authors read and approved the final manuscript.

Funding

Ministry of Science and Innovation. Spanish Government.

Availability of data and materials

Not applicable. 


\section{Declarations}

\section{Competing interests}

Not applicable.

Received: 3 November 2020 Accepted: 25 August 2021

Published online: 08 September 2021

\section{References}

Arthur, W. B. (2011). The nature of technology: What it is and how it evolves. Simon and Schuster.

Atman, C. J., Adams, R. S., Cardella, M. E., Turns, J., Mosborg, S., \& Saleem, J. (2007). Engineering design processes: A comparison of students and expert practitioners. Journal of Engineering Education, 96(4), 359-379.

Bagiati, A., Yoon, S. Y., Evangelou, D., Magana, A., Kaloustian, G., \& Zhu, J. (2015). The landscape of PreK-12 engineering online resources for teachers: global trends. International Journal of STEM Education. https://doi.org/10. 1186/s40594-014-0015-3

Becker, K., \& Park, K. (2011). Effects of integrative approaches among science, technology, engineering, and mathematics ( STEM ) subjects on students 'learning: A preliminary meta-analysis. Journal of STEM Education, 12(5), 23-38. https://doi.org/10.1037/a0019454

Blikstein, P. (2013). Digital Fabrication and 'Making' in Education: The Democratization of Invention. In J. Walter-Herrmann \& C. Büching (Eds.), FabLabs: Of Machines, Makers and Inventors (pp. 203-222). Transcript Publishers.

Boon, M. (2006). How science is applied in technology. International Studies in the Philosophy of Science, 20(1), 27-47. https://doi.org/10.1080/02698 590600640992

Bucciarelli, L. L. (2003). Engineering philosophy. International Journal of Machine Consciousness. https://doi.org/10.1142/S1793843010000369

Bunge, M. (2017). Philosophy of science: Volume 1, From problem to theory (Revised edn.).

Bybee, R. W. (1987). Science education and the science-technology-society (S-T-S) theme. Science Education, 71(5), 667-683.

Bybee, R. W. (2011). Scientific and engineering practices in K-12 classrooms. Science Teacher, 78(9), 34-40. https://doi.org/10.3917/rac.023.0226

Bybee, R. W. (2013). The case for STEM education: Challenges and opportunities. National Science Teachers Association.

Combemale, B., Cheng, B. H., Moreira, A., \& Bruel, J. (2016). Modeling for sustainability. In: Proceedings of the 8th International Workshop on Modeling in Software Engineering (pp. 62-66).

Couso, D., \& Garrido-Espeja, A. (2017). Models and modelling in pre-service teacher education: Why we need both. In J. Hahl, K. Juuti, K. Lampiselkä, J. Uitto, \& A. Lavonen (Eds.), Cognitive and affective aspects in science education research. 11th ESERA Conference Selected Contributions (pp. 245-261) Springer.

Couso, D., \& Simarro, C. (2020). STEM education through the epistemological lens: Unveiling the challenge of STEM transdisciplinarity. In C. C. Johnson, M. J. Mohr-Schroeder, T. J. Moore, \& L. D. English (Eds.), Handbook of research on STEM education (pp. 17-28). Taylor and Francis Inc.

Crismond, D. P., \& Adams, R. S. (2012). The informed design teaching and learning matrix. Journal of Engineering Education, 101(4), 738-797. https://doi. org/10.1002/j.2168-9830.2012.tb01127.x

Cunningham, C. M., \& Carlsen, W. S. (2014a). Precollege engineering education. In N. G. Lederman \& S. K. Abell (Eds.), Handbook of research on science education (pp. 747-758). Routledge.

Cunningham, C. M., \& Carlsen, W. S. (2014b). Teaching engineering practices. Journal of Science Teacher Education, 25(2), 197-210. https://doi.org/10. 1007/s10972-014-9380-5

Cunningham, C. M., \& Kelly, G. Y. J. (2017). Epistemic practices of engineering for education. Science Education, 101(3), 486-505. https://doi.org/10 1002/sce.21271

Deniz, H., Kaya, E., Yesilyurt, E., \& Trabia, M. (2019). The influence of an engineering design experience on elementary teachers' nature of engineering views. International Journal of Technology and Design Education. https:// doi.org/10.1007/s10798-019-09518-4

Dorie, B. L., Cardella, M. E., \& Svarovski, G. N. (2014). Capturing the Design Thinking of Young Children Interacting with a Parent Paper presented at
2014 ASEE Annual Conference \& Exposition, Indianapolis, Indiana. https:// doi.org/10.18260/1-2--20147

Duschl, R. A., \& Grandy, R. (2013). Two views about explicitly teaching nature of science. Science and Education, 22(9), 2109-2139. https://doi.org/10.1007/ s11191-012-9539-4

Dym, C. L., Agogino, A., Eris, O., Frey, D. D., \& Leifer, L. J. (2005). Engineering design thinking, teaching, and learning. Journal of Engineering Education. https://doi.org/10.1109/EMR.2006.1679078

English, L. D. (2016). STEM education K-12: Perspectives on integration. International Journal of STEM Education, 3(1), 3. https://doi.org/10.1186/ s40594-016-0036-1

English, L. D., \& King, D. T. (2015). STEM learning through engineering design: Fourth-grade students' investigations in aerospace. International Journal of STEM Education, 2(14), 1-18. https://doi.org/10.1186/ s40594-015-0027-7

Erduran, S., \& Dagher, Z. R. (2014). Reconceptualizing the nature of science education for science education. Scientific knowledge, practices and other family categories. Retrieved from http://legacy.lclark.edu/org/journal/

Erduran, S. (2020). Nature of "STEM"? Science \& Education, 29(4), 781-784. https://doi.org/10.1007/s11191-020-00150-6

Franssen, Maarten, Gert-Jan Lokhorst, and Ibo van de Poel, Philosophy of Technology, The Stanford Encyclopedia of Philosophy (Fall 2018 Edition), Edward N. Zalta (ed.), https://plato.stanford.edu/archives/fall2018/entri es/technology

Hansson, S. O. (2007). What is technological science? Studies in History and Philosophy of Science Part A, 38(3), 523-527. https://doi.org/10.1016/j. shpsa.2007.06.003

Hansson, S. O. (2015). Science and technology: What they are and why their relation matters. The role oftechnology in science: Philosophical perspectives (pp. 11-24). Springer. 10.1007/978-94-017-9762-7.

Harlen, W. (2010). Principles and big ideas of science education. Association for Science Education.

Honey, M., Pearson, G., \& Schweingruber, H. (2014). STEM integration in K-12 education (Committee on Integrated STEM Education; National Academy of Engineering; National Research Council (ed.)). The National Academies Press. 10.17226/18612.

ITEEA \& CTETE. (2020). Standards for technological and engineering literacy. ITEEA \& CTETE.

Jensen, L. S., Özkil, A. G., \& Mortensen, N. H. (2016). Prototypes in engineering design: Definitions and strategies. International Design Conference Design, 2016, 821-830.

Johnson, C. C., Mohr-Schroeder, M. J., Moore, T. J., \& English, L. D. (Eds.). (2020). Handbook of research on STEM education (1st ed.). Routledge.

Karatas, F. O., Micklos, A., \& Bodner, G. M. (2011). Sixth-grade students'views of the nature of engineering and images of engineers. Journal of Science Education and Technology, 20(2), 123-135. https://doi.org/10.1007/ s10956-010-9239-2

King, D., \& English, L. D. (2016). Engineering design in the primary school: Applying stem concepts to build an optical instrument. International Journal of Science Education, 38(18), 2762-2794. https://doi.org/10.1080/ 09500693.2016 .1262567

Li, Y., Schoenfeld, A. H., Andrea, A., Graesser, A. C., Benson, L. C., English, L. D., \& Duschl, R. A. (2019). Design and design thinking in STEM education. Journal for STEM Education Research, 2, 93-104. https://doi.org/10.1007/ s41979-019-00020-z

Lucas, B., Hanson, J., \& Claxton, G. (2014). Thinking like an engineer: Implications for the education system. London: Royal Academy of Engineering. https://www.raeng.org.uk/publications/reports/thinking-like-an-engin eer-implications-summary

Massachusetts Department of Elemantary and Secondary Education. (2016). 2016 Massachusetts science and technology/engineering curriculum framework. Massachusetts Department of Elemantary and Secondary Education.

Moote, J., Archer, L., Dewitt, J., \& Macleod, E. (2020). Comparing students 'engineering and science aspirations from age 10 to 16 : Investigating the role of gender, ethnicity, cultural capital, and attitudinal factors. Comparing Students' Engineering and Science Aspirations from Age 10 to 16: Investigating the Role of Gender Ethnicity, Cultural Capital, and Attitudinal Factors, 109, 34-51. https://doi.org/10.1002/jee.20302

NASA. (2009). Middle school and high school design packet. NASA. 
National Academy of Engineering and National Research Council. (2009). Engineering in K-12 education: Understanding the status and improving the prospects. National Academies Press.

National Research Council. (2012). A Framework for K-12 Science Education: Practices, Crosscutting Concepts, and Core Ideas. The National Academies Press. 10.17226/13165.

Oh, P. S., \& Oh, S. J. (2011). What teachers of science need to know about models: An overview. International Journal of Science Education, 33(8), 1109-1130. https://doi.org/10.1080/09500693.2010.502191

Ortiz-Revilla, J., Adúriz-Bravo, A., \& Greca, I. M. (2020). A framework for epistemological discussion on integrated STEM education. Science and Education, 29(4), 857-880. https://doi.org/10.1007/s11191-020-00131-9

Osborne, J. (2014). Teaching scientific practices: Meeting the challenge of change. Journal of Science Teacher Education, 25(2), 177-196. https://doi. org/10.1007/s10972-014-9384-1

Pacione, C. (2010). Evolution of the mind: A case for design literacy. Interactions. https://doi.org/10.1145/1699775.1699777

Park, W., Wu, J., \& Erduran, S. (2020). The nature of STEM disciplines in the science education standards documents from the USA, Korea and Taiwan Focusing on Disciplinary Aims, Values and Practices. Science \& Education. https://doi.org/10.1007/s11191-020-00139-1

Pleasants, J., \& Olson, J. K. (2019). What is engineering? Elaborating the nature of engineering for K-12 education. Science Education, 103(1), 145-166. https://doi.org/10.1002/sce.21483
Sanders, M. (2009). STEM, STEM education stemania. Education, 68(4), 20-27. Sharp, J. J. (1991). Methodologies for problem solving: An engineering approach. The Vocational Aspect of Education ISSN, 42(114), 147-157. https://doi.org/10.1080/10408347308003631

Sinclair, M. (1993). On the differences beetween the engineering and scientific methods. International Journal of Engineering Education, 9(5), 358-361.

Sokolowski, A. (2018). Scientic inquiry in mathematics-Theory and practice. A STEM Perspective. https://doi.org/10.1007/978-3-319-89524-6

TeachEngineering. (2009). Engineering Design Process. Teach Engineering. STEM curriculum for K-12. https://www.teachengineering.org/k12en gineering/designprocess.

Vincenti, W. (1990). What engineers know and how they know it. Johns Hopkins University Press.

Wang, J., Werner-Avidon, M., Newton, L., Randol, S., Smith, B., \& Walker, G. (2013). Ingenuity in Action: Connecting Tinkering to Engineering Design Processes. Journal of Pre-College Engineering Education Research, 3(1), 1-21. https://doi.org/10.7771/2157-9288.1077

\section{Publisher's Note}

Springer Nature remains neutral with regard to jurisdictional claims in published maps and institutional affiliations.

\section{Submit your manuscript to a SpringerOpen ${ }^{\circ}$ journal and benefit from:}

- Convenient online submission

- Rigorous peer review

- Open access: articles freely available online

- High visibility within the field

- Retaining the copyright to your article

Submit your next manuscript at $\boldsymbol{\nabla}$ springeropen.com 